\title{
ERRATUM
}

\section{The interpretation of gene conversion data from ordered eight-spored asci}

\author{
By J. R. S. FINCHAM, W. G. HILL AND E. C. R. REEVE
}

Genetical Research, Vol. 35, No. 2, 1980

On p. 181 the phrases 'wild to mutant' and 'mutant to wild' in lines 8-9 in the third paragraph should be interchanged: $p$ and $r$ are correction frequencies from mutant to wild and $q$ and $s$ are correction frequencies from wild to mutant, as is apparent in the Table immediately following.

On p. 188 the calculated ratios $p / q$ and $r / s$ may appear to be at variance with the values given in Table 2 . This is due to the latter having been rounded to two significant figures. The more accurate values for the $+\times h_{3}$ cross are as follows: $p=0.043, q=0.161, r=0.157, s=0.426$ (first solution) and $p^{\prime}=0.026, q^{\prime}=0.493$, $r^{\prime}=0.243$ and $s^{\prime}=0.128$ (second solution).

On p. 191 (foot of page) some primes are misplaced. The correct formulae for $r, q$ and $s$ (as given on p. 182) are:

$$
r=\frac{Y}{X^{\prime}+Y+X^{\prime} Y^{\prime}}, \quad q=\frac{X}{X+Y^{\prime}+X Y^{\prime}}, \quad s=\frac{X^{\prime}}{X^{\prime}+Y+X^{\prime} Y}
$$

On p. 194, line 7, $G=2 B+C$ should read $G=2 B+D$.

We are grateful to Drs B. C. Lamb and P. Thuriaux for having pointed out some of these errors. 